\title{
Control Strategy for Grid Connected Inverters Under Unbalanced Network Conditions - A DOb Based Decoupled Current Approach
}

\author{
Emre Ozsoy ${ }^{1}$, Sanjeevikumar Padmanaban ${ }^{1}{ }^{*}$, Lucian Mihet-Popa ${ }^{2}$, Viliam Fedák ${ }^{3}$, \\ Fiaz Ahmad ${ }^{4}$, Rasool Akhtar ${ }^{4}$, Asif Sabanovic ${ }^{4}$ \\ 1 Department of Electrical and Electronics Engineering, University of Johannesburg, Auckland Park, South \\ Africa ; eemreozsoy@yahoo.co.uk, sanjeevi_12@yahoo.co.in \\ 2 Faculty of Engineering, Østfold University College, Kobberslagerstredet 5, 1671 Kråkeroy; Building: S \\ 316, Norway ; lucian.mihet@hiof.no \\ 3 Department of Electrical Engineering \& Mechatronics, Technical University of Kosice, Rampová 1731/7, \\ 04001 Košice - Džungla-Džungla, Slovakia; viliam.fedak@tuke.sk \\ 4 Mechatronics Engineering, Faculty of Engineering and Natural Sciences, Sabancı University, Istanbul, \\ Turkey ; fiazahmad@sabanciuniv.edu; akhtar@sabanciuniv.edu; asif@sabanciuniv.edu \\ * Correspondence sanjeevi_12@yahoo.co.in; Tel.: +27-79-219-9845
}

\begin{abstract}
Penetration of grid connected inverters (GCI) has arisen in power systems due to increasing integration of renewable sources. However, restrictive grid codes require that renewable sources connected to the grid with power electronic systems must be properly connected and appropriate currents must be injected to support stability of the grid under grid faults. Simultaneous injection of symmetrical positive and negative sequence currents is mandatory to support stabilization of grid at the instant of grid faults. Conventional synchronously rotating frame dq current controllers are insufficient under grid faults due to low bandwidth of PI controllers. This paper proposes a new grid current control strategy for grid connected voltage source inverters under unbalanced grid voltage conditions. A proportional current controller with a first order low pass filter disturbance observer $(\mathrm{DOb})$ is proposed which establishes positive sequence power requirements and independently control negative sequence current components under unbalanced voltage conditions. The method does not need any parameter, since it estimates nonlinear terms with low pass filter DOb. Simulations are implemented in Matlab/Simulink platform demonstrating the effectiveness of proposed method.
\end{abstract}

Keywords: power control; power electronics; pwm inverters; disturbance observer; grid connected system; grid stability; distorted voltage

PACS: J0101

\section{Introduction}

Rapid penetration of renewable energy sources connected to the grid and distribution systems with power electronic circuits have changed the expected grid requirements to guarantee an appropriate performance under grid faults. In addition to performance and reliability of the system performed through power electronic circuits in normal conditions, stability and grid support under grid faults are crucial due to restrictive grid code requirements [1,2].

In particular, the most common fault type in electrical networks is unbalanced voltage conditions which can easily happen in any voltage sags, and causes double frequency power oscillations. In addition to required positive sequence $\mathrm{P}$ and $\mathrm{Q}$ injection by renewable source (RES) through GCI, these oscillations must be compensated by injecting appropriate negative sequence current sets. However, this aim cannot be realized by using conventional methods. 
PI controller based vector control method for GCI structures considering balanced voltage conditions are given in [3]. This method decouples grid currents into $\mathrm{P}$ and $\mathrm{Q}$ generating components, and proportional-integral (PI) current controllers achieve stable operation. However, this popular structure is fragile under voltage problems due to low bandwidth of PI controllers.

One of the first contributions related to control of GCI under unbalanced voltage is given in [4,5] by using decoupled Proportional-Integral (PI) control of positive and negative sequence dq frames. This structure is also known as double synchronous reference frame (DSRF) method and used by many researchers [6,7]. Proportional-Resonant (PR) [8,9] controllers are also extensively used for GCI which feed forwards a resonant controller tuned at double of the grid frequency. Direct power control methods $[10,11]$ control the required power without additional inner current loops. Method given in [12] gives an enhanced operation of decoupled double synchronous reference frame (DDSRF) operation by using feed forwarded resonant controllers. Model based predictive control $[13,14]$ methods minimizes the cost function by predicting the future current and power components of GCI under unbalanced voltage operation.

Decoupled control of synchronously rotating positive and negative sequence dq currents as given in [6,7] is an effective method for control of GCI. However, this method suffers from simultaneously dissipating active and reactive oscillating components. Instantaneous power theory calculations based independent $\mathrm{P}$ and $\mathrm{Q}$ control strategy is given in [15] by proposing different current reference calculations depending on power requirements. A robust power flow algorithm which is based on disturbance rejection control algorithm is given in [16]. These methods given in [13-16] can independently dissipate $P$ and $Q$ double frequency oscillations. However, the shape and magnitude of non-sinusoidal injected currents highly increases current harmonics in the system, which limits the effectiveness of these methods.

Three phase four leg inverters can generate sinusoidal voltage waveform in a wide range of nonlinear operating conditions for more sensitive loads, such as data transfer and military purposes, since they also can issue power quality requirements [17, 18]. However, additional phase leg and inductance complicates the circuit and reduces the overall efficiency.

Grid synchronization is of great importance for robust control of GCI, fast and accurate estimation of grid voltage parameters is essential to operate under grid faults. Different PLL algorithms are available in the literature aiming to operate under grid voltage problems [19-22]. It is assumed in this study that symmetrical positive and negative sequence component decomposition of the grid voltage is properly realized, such as given in [23] under grid faults.

Disturbance observer $(\mathrm{DOb})$ based controller is a simple and robust structure which estimates external disturbances and uncertainties, thus the effect of disturbances and uncertainties are suppressed [24]. Estimated disturbances and system uncertainties are fed-forward to inner control loop, thus the robustness of the system is obtained. An additional external controller could be cascaded to achieve desired performance goals, such as power and/or speed in electrical systems, since $\mathrm{DOb}$ controls uncertain plant and removes the effect of external disturbances in the inner control loop.

$\mathrm{DOb}$ based current controller is applied to doubly fed induction generators (DFIG) and GCI in $[25,26]$ by considering robustness against parameter variations under balanced voltage sets. However, this method must be carefully tuned to suppress double frequency oscillations. This study models the grid dynamic model in synchronously rotating symmetrical positive and negative sequence dq frame. Therefore, decoupled positive and negative sequence dq current components are independently controlled by achieving robust control under grid voltage faults. In addition to the availability of simultaneous positive and negative sequence current injection, the proposed method is not affected by other external disturbances and uncertainties such as grid impedance variations.

Integral terms in conventional PI controllers must be carefully tuned to prevent unwanted overshoots for a wide range of operation. In addition, wind up effect of integrator must be considered for real time systems. Instead of conventional PI controllers and fed-forwarded parameter dependent cross coupling terms, proposed proportional controller with a low pass filter 
$\mathrm{DOb}$ is sufficient for robust operation, since $\mathrm{DOb}$ accurately estimates and feed forwards uncertain terms. The control structure is simple and can be applied in real time systems.

The contribution of this study is a proportional decoupled current controller with fed-forwarded low pass filter $\mathrm{DOb}$ which satisfies positive sequence power requirements by independently controlling negative sequence currents. This is the first study for decoupled dq current control structure by using symmetrical component decomposition and estimating the disturbances with DOb concept. The study is implemented on Matlab/Simulink simulation platform.

\section{Dynamic Model}

Equivalent circuit of GCI is given in Fig.1 in abc frame. The system is connected to the grid with respective grid resistance and inductance values. Dynamic model can be rewritten either stationary or synchronously rotating dq frame according to given equivalent circuit.

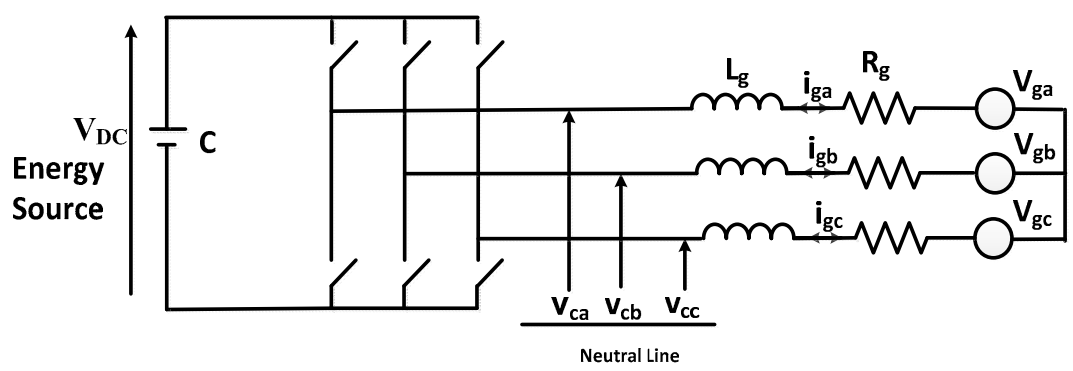

Figure 1. Equivalent Circuit of GSC in abc frame

The three phase electrical variables such as current, voltage etc. could be indicated in several different types of reference frames [31, 32]. Two orthogonal synchronously rotating components in $\mathrm{dq}$ frame are sufficient, if the balanced system representation is required. However, it is insufficient in case of unbalanced systems representation, and respective positive and negative sequence components must be presented.

The dynamical model could be arranged in the orthogonal frame of references associated with positive and negative symmetrical component of the grid voltage, where positive sequence (dq)+ frames is composed of balanced voltage, while unbalanced voltage component generates negative sequence (dq)- frame which is given in Fig.2.

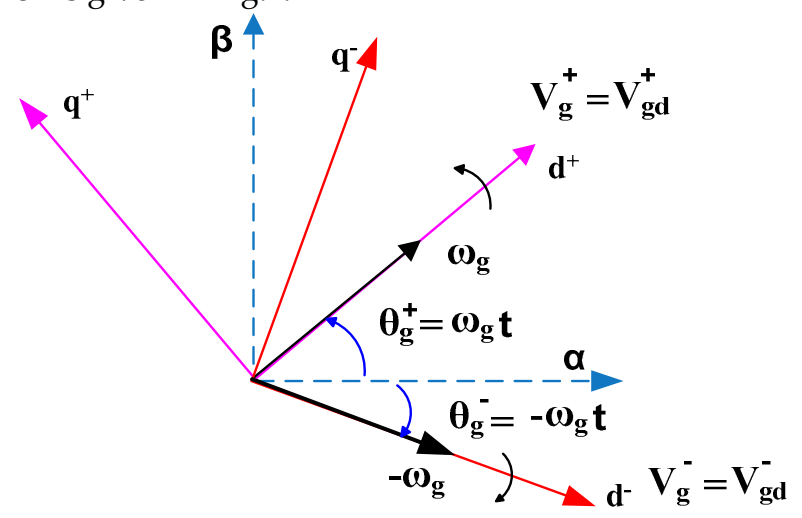

Figure 2. Orthogonal (dq)+ and (dq)- frames of references

Current equation in symmetrical (dq)+ and (dq)- frames can be written as;

$$
\mathbf{L}_{\mathrm{g}} \frac{\mathbf{d i} \mathbf{g}_{\mathrm{g}}}{\mathbf{d t}}=\mathbf{v}_{\mathrm{s}}-\mathbf{R}_{\mathrm{g}} \mathbf{i}_{\mathrm{g}}+\mathbf{L} \mathbf{i}_{\mathrm{g}}-\mathbf{v}_{\mathrm{g}}
$$

Where 


$$
\begin{aligned}
& \mathbf{i}_{\mathbf{g}}^{\mathbf{T}}=\left[\begin{array}{llll}
\mathbf{i}_{\mathbf{g d}}^{+} & \mathbf{i}_{\mathbf{g q}}^{+} & \mathbf{i}_{\mathbf{g d}}^{-} & \mathbf{i}_{\mathbf{g q}}^{-}
\end{array}\right], \mathbf{v}_{\mathbf{g}}^{\mathbf{T}}=\left[\begin{array}{llll}
\mathbf{v}_{\mathbf{g d}}^{+} & \mathbf{v}_{\mathrm{gq}}^{+} & \mathbf{v}_{\mathbf{g d}}^{-} & \mathbf{v}_{\mathbf{g q}}^{-}
\end{array}\right], \mathbf{v}_{\mathbf{s}}^{\mathbf{T}}=\left[\begin{array}{llll}
\mathbf{v}_{\mathbf{s d}}^{+} & \mathbf{v}_{\mathbf{s q}}^{+} & \mathbf{v}_{\mathbf{s d}}^{-} & \mathbf{v}_{\mathbf{s q}}^{-}
\end{array}\right] \\
& \mathbf{L}_{g}=\operatorname{diag}\left[\begin{array}{llll}
\mathbf{L}_{g} & \mathbf{L}_{\mathrm{g}} & \mathbf{L}_{\mathrm{g}} & \mathbf{L}_{\mathrm{g}}
\end{array}\right], \mathbf{L}_{\mathrm{g}}=\operatorname{diag}\left[\mathbf{R}_{\mathrm{g}} \quad \mathbf{R}_{\mathrm{g}} \quad \mathbf{R}_{\mathrm{g}} \quad \mathbf{R}_{\mathrm{g}}\right] \\
& \mathbf{L}=\left[\begin{array}{cccc}
\mathbf{0} & \omega_{\mathrm{g}} \mathbf{L}_{\mathrm{g}} & \mathbf{0} & \mathbf{0} \\
\omega_{\mathrm{g}} \mathbf{L}_{\mathrm{g}} & \mathbf{0} & \mathbf{0} & \mathbf{0} \\
\mathbf{0} & \mathbf{0} & \mathbf{0} & \omega_{\mathrm{g}} \mathbf{L}_{\mathrm{g}} \\
\mathbf{0} & \mathbf{0} & \omega_{\mathrm{g}} \mathbf{L}_{\mathrm{g}} & \mathbf{0}
\end{array}\right]
\end{aligned}
$$

The terms $i_{g}, \mathrm{Vg}$, represent grid currents and voltages in the synchronously rotating dq frame. The term, vs is GCI output voltage. The terms $\mathrm{R}_{\mathrm{g}}$ and $\mathrm{Lg}$ represent grid resistances and inductances. All diagonal element of $\mathrm{Lg}$ and $\mathrm{R}_{\mathrm{g}}$ matrix for symmetrical systems are equal. The meaning of superscripts $+/$ - are for $(\mathrm{dq})+$ and $(\mathrm{dq})$ - rotating frames, respectively. $\mathrm{d} / \mathrm{q}$ subscript means dq rotating frames. The term $\omega_{\mathrm{g}}$ is for grid electrical speed. The rotating frame is aligned with $\mathrm{d}$ axis, and $\mathrm{v}_{\mathrm{q}}=0$. The line currents are assumed to be measured, and GCI output generated voltage is known. GCI circuit can be written as given below.

$$
\frac{d i_{g}}{d t}=L_{g}^{-1} v_{s}-\underbrace{L_{g}^{-1} R_{g} i_{g}+L_{g}^{-1} L i_{g}-L_{g}^{-1} v_{g}}_{f_{g}}
$$

The term, $f_{g}{ }^{T}=\left[\begin{array}{llll}f_{g d}^{+} & f_{g q}^{+} & f_{g d}^{-} & f_{g q}^{-}\end{array}\right]$are nonlinear and accurate determination of grid and GCI parameters are required to define these terms. That is impractical and $f_{g}$ is considered as disturbance. Control performance can be written as;

$$
\varepsilon_{\mathrm{g}}=\mathbf{i}_{\mathrm{g}}^{\mathrm{ref}}-\mathbf{i}_{\mathrm{g}}
$$

Where $\varepsilon_{\mathrm{g}}^{\mathrm{T}}=\left[\begin{array}{llll}\varepsilon_{\mathrm{gd}}^{+} & \varepsilon_{\mathrm{gq}}^{+} & \varepsilon_{\mathrm{gd}}^{-} & \varepsilon_{\mathrm{gq}}^{-}\end{array}\right]$is error of control performance. If (5) is inserted into the derivative of (6), the error dynamics can be given as;

$$
\frac{d \varepsilon_{g}}{d t}=-L_{g}^{-1} v_{s}+\underbrace{\left(f_{g}+\frac{d_{i g}^{r e f}}{d t}\right)}_{f_{g}}
$$

Closed loop error equation is given as follows;

$$
\frac{\mathrm{d} \varepsilon_{\mathrm{g}}}{\mathrm{dt}}+\mathbf{k}_{\mathrm{g}} \varepsilon_{\mathrm{g}}=\mathbf{0}
$$

The term $\quad \mathrm{k}_{\mathrm{g}}^{\mathrm{T}}=\operatorname{diag}\left[\begin{array}{lllll}\mathrm{k}_{\mathrm{gd}}^{+} & \mathrm{k}_{\mathrm{gq}}^{+} & \mathrm{k}_{\mathrm{gd}}^{-} & \mathrm{k}_{\mathrm{gq}}^{-}\end{array}\right]$is a positive controller gain. Error of control performance $\varepsilon_{\mathrm{g}}$ is defined as asymptotic convergence to zero. The definition of convergence speed is dependent on the value of $\mathrm{kg}$ coefficients. If (7) is inserted into (8), applied generated voltages to GCI is written as follows;

$$
\mathbf{L}_{\mathrm{g}}^{-1} \mathbf{v}_{\mathrm{s}}=\mathbf{f}_{\mathrm{g}}+\mathbf{k}_{\mathrm{g}} \varepsilon_{\mathrm{g}}
$$

Grid inductance base value, $\mathrm{Lg}$ is insensitive to disturbances. Thus, voltages applied for GCI is written below.

$$
\mathbf{v}_{\mathbf{s}}^{\text {ref }}=\underbrace{\mathbf{L}_{\mathbf{g}} \mathbf{f}_{\mathbf{g}}}_{\mathbf{f}_{\mathbf{g}}}+\mathbf{L}_{\mathbf{g}} \mathbf{k}_{\mathbf{g}} \varepsilon_{\mathrm{g}}
$$

\subsection{First Order Low Pass Filter Disturbance Observer}

The term, $\mathrm{f}_{\mathrm{g}}$ can be estimated by modifying the voltage equations. If (8) is inserted in (9), determination of the grid voltage is possible to enforce desired control performance in the current loop. The disturbance terms are considered as bounded and defined by $\dot{\mathrm{f}}_{\mathrm{g}}=0$ with unknown initial conditions [32]. System inputs and outputs ( $\mathrm{v}_{\mathrm{c}}$ and $\mathrm{i}_{\mathrm{g}}$ ) are considered to be known or measured. 


$$
f_{g}=v_{s}-L_{g} \frac{d i_{g}}{d t}
$$

First order low pass filter DOb is applied to (11) in s domain as given below.

$$
\hat{\mathbf{f}}_{\mathrm{g}}=\mathbf{T}\left(\mathbf{v}_{s}-\mathbf{s} \mathbf{L}_{\mathrm{g}} \mathbf{i}_{\mathrm{g}}\right)
$$

Where $\mathbf{T}^{\mathrm{T}}=\operatorname{diag}\left[\begin{array}{llll}\frac{\mathrm{g}_{\mathrm{d}}^{+}}{\mathrm{s}+\mathrm{g}_{\mathrm{d}}^{+}} & \frac{\mathrm{g}_{\mathrm{q}}^{+}}{\mathrm{s}+\mathrm{g}_{\mathrm{q}}^{+}} & \frac{\mathrm{g}_{\mathrm{d}}^{-}}{\mathrm{s}+\mathrm{g}_{\mathrm{d}}^{-}} & \frac{\mathrm{g}_{\mathrm{q}}^{-}}{\mathrm{s}+\mathrm{g}_{\mathrm{q}}^{-}}\end{array}\right]$

The term, s is the Laplace operator. The coefficients, ggd and ggq are the cut-off frequency gains. The block diagram of disturbance observer could be drawn as given in Fig. 3 .

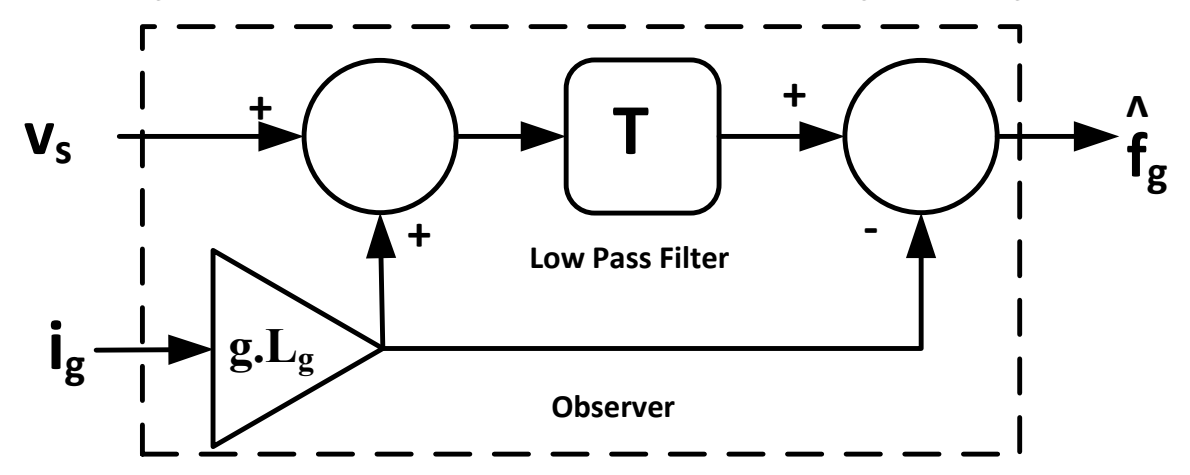

Figure 3. Disturbance Observer (DOb) Block Diagram

The final grid current error equations are given by;

$$
\frac{\mathbf{d} \varepsilon_{g}}{\mathbf{d t}}+\mathbf{k}_{\mathrm{g}} \varepsilon_{\mathrm{g}}=\mathbf{f}_{\mathrm{g}}-\hat{\mathbf{f}}_{\mathrm{g}}
$$

It can be stated from (13) that the right hand side tend towards zero as given below. The optimal selection of the low pass filter parameter is to set [T] = diag[1] in the frequency range in which disturbance is expected. The bandwidth of $\mathrm{DOb}$ should be as high as possible, so disturbance error can converge to zero in a wide range of frequency. DOb compensation error will converge to zero in practical terms with proper selection of cut of frequency [27]. This estimated disturbance plays a very critical role in the controller structure as a feed forward term, and does not influence the stability of the closed loop controller structure with the properly selected cut-off frequencies. Because of the effectiveness of feed forward disturbance term, the integral action is not required in the closed loop structure. Therefore, proportional controller with a positive definite $\mathrm{kg}_{\mathrm{g}}$ value is sufficient that the controller error converges to zero in finite time. As a result, proposed controller structure is more robust and simple compared to conventional PI controllers, since it estimates and feed forwards the disturbance terms without integral part of the controller.

\subsection{Instantaneous Power Equations}

The instantaneous powers associated with unbalanced current and voltage components can be written in the following form [29] with multiplication of double frequency oscillating components.

$$
\left[\begin{array}{l}
P(t) \\
Q(t)
\end{array}\right]=\left[\begin{array}{l}
P_{g 0} \\
Q_{g 0}
\end{array}\right]+\left[\begin{array}{l}
P_{s c 2} \\
Q_{s c 2}
\end{array}\right] \cos \left(2 \omega_{g} t\right)+\left[\begin{array}{l}
P_{s s 2} \\
Q_{s s} 2
\end{array}\right] \sin \left(2 \omega_{g} t\right)
$$

Where;

$$
\left[\begin{array}{c}
P_{g 0} \\
Q_{g 0}
\end{array}\right]=1.5\left[\begin{array}{cccc}
v_{g d}^{+} & v_{g q}^{+} & v_{g d}^{-} & v_{g d}^{-} \\
v_{g q}^{+} & -v_{g d}^{+} & v_{g q}^{-} & -v_{g d}^{-}
\end{array}\right]\left[\begin{array}{c}
i_{g d}^{+} \\
i_{g q}^{+} \\
i_{g d}^{-} \\
i_{\text {gq }}^{-}
\end{array}\right]
$$




$$
\begin{gathered}
{\left[\begin{array}{l}
P_{s c 2} \\
Q_{s c 2}
\end{array}\right]=1.5\left[\begin{array}{cccc}
v_{g d}^{-} & v_{g q}^{-} & v_{g d}^{+} & v_{g q}^{+} \\
v_{g q}^{-} & -v_{g d}^{-} & v_{g q}^{+} & -v_{g d}^{+}
\end{array}\right]\left[\begin{array}{c}
i_{g d}^{+} \\
i_{g q}^{+} \\
i_{g d}^{-} \\
i_{g q}^{-}
\end{array}\right]} \\
{\left[\begin{array}{c}
P_{s s 2} \\
Q_{s s 2}
\end{array}\right]=1.5\left[\begin{array}{cccc}
v_{g q}^{-} & -v_{g d}^{-} & -v_{g q}^{+} & v_{g d}^{+} \\
-v_{g d}^{-} & -v_{g q}^{-} & v_{g d}^{+} & v_{g q}^{+}
\end{array}\right]\left[\begin{array}{c}
i_{g d}^{+} \\
i_{g q}^{+} \\
i_{g d}^{-} \\
i_{g q}^{-}
\end{array}\right]}
\end{gathered}
$$

The terms, $\mathrm{P}_{\mathrm{g} 0}$ and $\mathrm{Q}_{\mathrm{g} 0}$ are fundamental instantaneous active and reactive power components which consist of positive and negative sequence power equations, while the terms $P_{\text {sc2 }}-P_{\text {ss2 } 2}$ and $\mathrm{Q}_{\mathrm{sc2} 2} \mathrm{Q}_{\mathrm{ss2}}$ are four pulsating terms which is the resultant of asymmetrical network conditions. Maximum 4 variables $\left(\mathrm{i}_{\mathrm{gd}}^{+} \quad \mathrm{i}_{\mathrm{gq}}^{+} \quad \mathrm{i}_{\mathrm{gd}}^{-} \quad \mathrm{i}_{\mathrm{gq}}^{-}\right.$) could be controlled to achieve $\mathrm{P}_{\mathrm{g} 0}$ and $\mathrm{Q}_{\mathrm{g} 0}$ requirements and compensate $\mathrm{P}_{\mathrm{sc2} 2} \mathrm{P}_{\mathrm{ss} 2}$ and $\mathrm{Q}_{\mathrm{sc2}}-\mathrm{Q}_{\mathrm{ss} 2}$ oscillating components. Thus, active and reactive power oscillations cannot be compensated simultaneously in positive and negative sequence dq frame [28]. It is necessary to calculate appropriate set of current references to ensure a constant value of active power absorbed or injected by GCI under balanced and unbalanced voltage conditions. These $\mathrm{P}_{\mathrm{g} 0}$ and $\mathrm{Q}_{\mathrm{g} 0}$ requirements and $\mathrm{P}_{\mathrm{sc} 2}-\mathrm{P}_{\mathrm{ss} 2}$ oscillation compensation can be addressed by using the following expression.

$$
\left[\begin{array}{l}
\mathrm{P}_{\mathrm{g} 0} \\
\mathrm{Q}_{\mathrm{g} 0} \\
\mathrm{P}_{\mathrm{sc2}} \\
\mathrm{P}_{\mathrm{ss} 2}
\end{array}\right]=1.5\left[\begin{array}{cccc}
\mathrm{v}_{\mathrm{gd}}^{+} & \mathrm{v}_{\mathrm{gq}}^{+} & \mathrm{v}_{\mathrm{gd}}^{-} & \mathrm{v}_{\mathrm{gq}}^{-} \\
\mathrm{v}_{\mathrm{gq}}^{+} & -\mathrm{v}_{\mathrm{gd}}^{+} & \mathrm{v}_{\mathrm{gq}}^{-} & -\mathrm{v}_{\mathrm{gd}}^{-} \\
-\mathrm{v}_{\mathrm{gd}}^{-} & \mathrm{v}_{\mathrm{gq}}^{-} & \mathrm{v}_{\mathrm{gd}}^{+} & \mathrm{v}_{\mathrm{gq}}^{+} \\
\mathrm{v}_{\mathrm{gq}}^{-} & -\mathrm{v}_{\mathrm{gd}}^{-} & -\mathrm{v}_{\mathrm{gq}}^{+} & \mathrm{v}_{\mathrm{gd}}^{+}
\end{array}\right]\left[\begin{array}{c}
\mathrm{i}_{\mathrm{gd}}^{+} \\
\mathrm{i}_{\mathrm{gq}}^{+} \\
\mathrm{i}_{\mathrm{gd}}^{-} \\
\mathrm{i}_{\mathrm{gq}}^{-}
\end{array}\right]
$$

Eq. (18) defines that positive sequence grid current controllers achieve $\mathrm{P}$ and $\mathrm{Q}$ requirements, while negative sequence current controllers can compensate the active power oscillations depending on the negative sequence current injection strategy. The proposed scheme is depicted in Fig. 4. If zero $\mathrm{i}_{\mathrm{gd}}^{-}$and $\mathrm{i}_{\mathrm{gd}}^{-}$references are chosen, injected currents towards the grid are sinusoidal, this supports power quality requirements. If zero $\mathrm{P}_{\mathrm{sc} 2}-\mathrm{P}_{\mathrm{ss} 2}$ reference selection is selected, double frequency oscillating power components can be compensated by injecting negative sequence currents towards the grid. The proportional current controllers are sufficient to track the desired current requirements with accurately estimated disturbance terms. Online SOGI based symmetrical component estimation is achieved with the method given in [23]. PLL structures separately calculate symmetrical voltage phase and angle. It is assumed that symmetrical component decomposition of voltage and currents are perfectly estimated and accurate PLL voltage phase and angle estimation is achieved. 


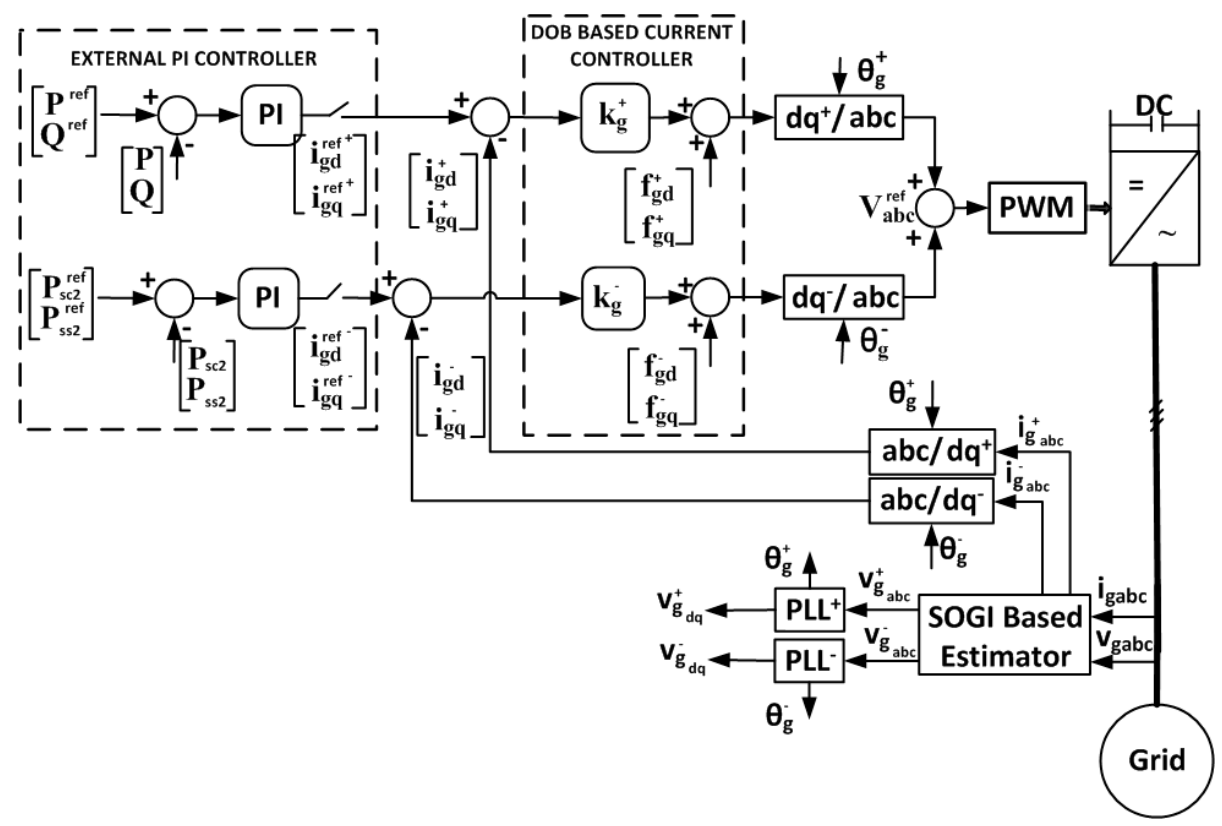

Figure 4. Proposed Controller Structure

\section{Simulation Results}

Fig.5 depicts the simulation circuit in Matlab/Simulink SimPowerSystem platform. GCI is connected to a transmission system, and all necessary parameters for simulation are given in Table 1. Three different simulations are implemented to validate the proposed controller structure. First simulation demonstrates positive sequence controller without enabling negative sequence controller to show the deteriorated current and power waveforms under unbalanced voltage conditions (Simulation A). Dual current controller with enabled negative sequence current controller enforces negative sequence currents to zero in second simulation (Simulation B). Third simulation enforces double frequency $\mathrm{P}_{\mathrm{sc} 2}-\mathrm{P}_{\mathrm{ss} 2}$ power oscillations to zero. In addition, dynamic performance of positive sequence controllers will be demonstrated by applying appropriate dq current steps (Simulation C).

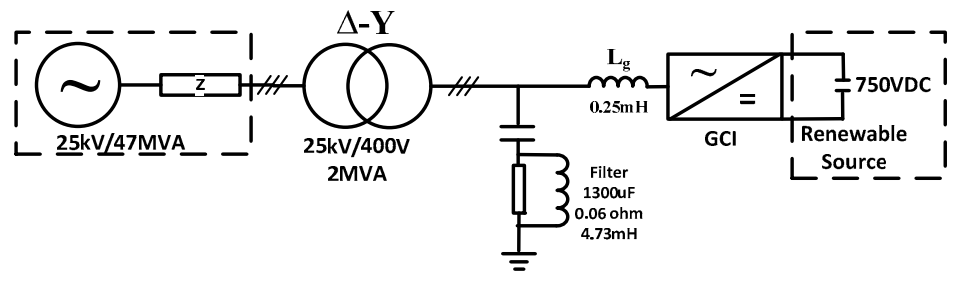

Figure 5. Simulation Circuit

DC voltage is kept constant at $750 \mathrm{~V}$ to reduce the harmonic stress in the currents which means Renewable Energy Source (RES) is connected to the DC bus and can inject required power to the grid at any instant of simulation. Reference of $i_{g d}^{+}$is kept at $150 \mathrm{~A}$ meaning that the injection of currents are applied towards the grid. Reference of $\mathrm{i}_{\mathrm{gq}}^{+}$is kept at $0 \mathrm{~A}$ to ensure the zero reactive power injection. Applied steps at different instants of Simulation A and B are given as follows;

0.20-0.25s: $30 \%$ unbalanced voltage condition is generated on phase- $\mathrm{A}$ in the grid.

0.30-0.33s: $i_{\text {gd }}^{+}$reference step is applied from $150 \mathrm{~A}$ to $300 \mathrm{~A}$, 
0.38-0.43s: $\mathrm{i}_{\mathrm{gq}}^{+}$reference step is applied from $0 \mathrm{~A}$ to $100 \mathrm{~A}$

\begin{tabular}{lcc}
\hline \multicolumn{1}{c}{ Symbol } & Quantity & Unit \\
\hline GCI DC Voltage & 750 & Volt \\
Nominal GCI Current & 500 & $\mathrm{~A}$ \\
Nominal GCI Power & 350 & $\mathrm{KVA}$ \\
Switching Frequency & 10 & $\mathrm{kHz}$ \\
Lg Filter of GCI & 0.25 & $\mathrm{mH}$ \\
X/R Ratio of Grid & 7 & - \\
$\mathrm{KP}(+) / \mathrm{KP}_{(-)}$ & 20 & - \\
$\mathrm{gd}_{\mathrm{d}}$ & 500 & radian \\
\hline
\end{tabular}

Fig.6 shows the first simulation results (Simulation A) with disabled negative sequence controller. $30 \%$ unbalanced voltage on phase-A between $0.25-0.30$ s is applied which is shown in Fig.6a. Sinusoidal grid currents are shown Fig. $6 \mathrm{~b}$ that the sinusoidal shape is deteriorated without negative sequence current controller. Respective $\mathrm{i}_{\text {gd }}^{+}$and $\mathrm{i}_{\text {gq }}^{+}$step response tests are shown in Fig. 6c. Fig. 6d shows the respective $\mathrm{dq}$ axis current references that change the $\mathrm{P}_{\mathrm{g}}$ and $\mathrm{Q}_{\mathrm{g}}$ properly. Performance criteria is satisfied with DOb based current controllers without any steady state error and overshoot. Double grid frequency power oscillations exist under unbalanced voltage, and can only be dissipated by injecting negative sequence currents.

Similarly, Fig.7 shows the second simulation results (Simulation B) with dual positive and negative sequence current controller results. Negative sequence controller is only enabled when the unbalanced voltage exists in the grid. Because, it is observed in simulations that enabling the negative sequence controller in balanced voltage conditions unnecessarily deteriorates the dynamic performance of the overall system [33]. Thus, a simple logic condition is added in simulation to enable or disable negative sequence controller depending on the negative sequence voltage level. Negative sequence current components are enforced to zero at the instant of unbalanced voltage condition, and deteriorated current waveforms are dissipated as shown in Fig. $7 \mathrm{~b}$. Double frequency oscillations still exist in power components as shown in Fig. 7d.

Fig. 8 and Fig. 9 shows the estimated disturbances and negative sequence current components with (Simulation B) and without (Simulation A) negative sequence current controller. Fig.8a and $8 \mathrm{~b}$ shows the fed forwarded $\hat{\mathrm{f}}_{\mathrm{gd}}^{+}-\hat{\mathrm{f}}_{\mathrm{gq}}^{+}$and $\hat{\mathrm{f}}_{\mathrm{gd}}^{-}-\hat{\mathrm{f}}_{\mathrm{gq}}^{-}$terms. The term $\hat{\mathrm{f}}_{\mathrm{gd}}^{+}$saturates to maximum level at the instant of unbalanced voltage condition to remove steady state current errors. Fig. 8c shows that negative sequence current components are removed at the instant of unbalance voltage generation in the grid (Simulation B). Fig. 9a shows the $\hat{\mathrm{f}}_{\mathrm{gd}}^{+}-\hat{\mathrm{f}}_{\mathrm{gq}}^{+}$terms when the negative sequence controller is not enabled at the instant of unbalanced voltage generation (Simulation A). Fig. 9b shows the uncompensated negative sequence current components exists and deteriorates the current waveform as shown in Fig. 6 b (Simulation A). 

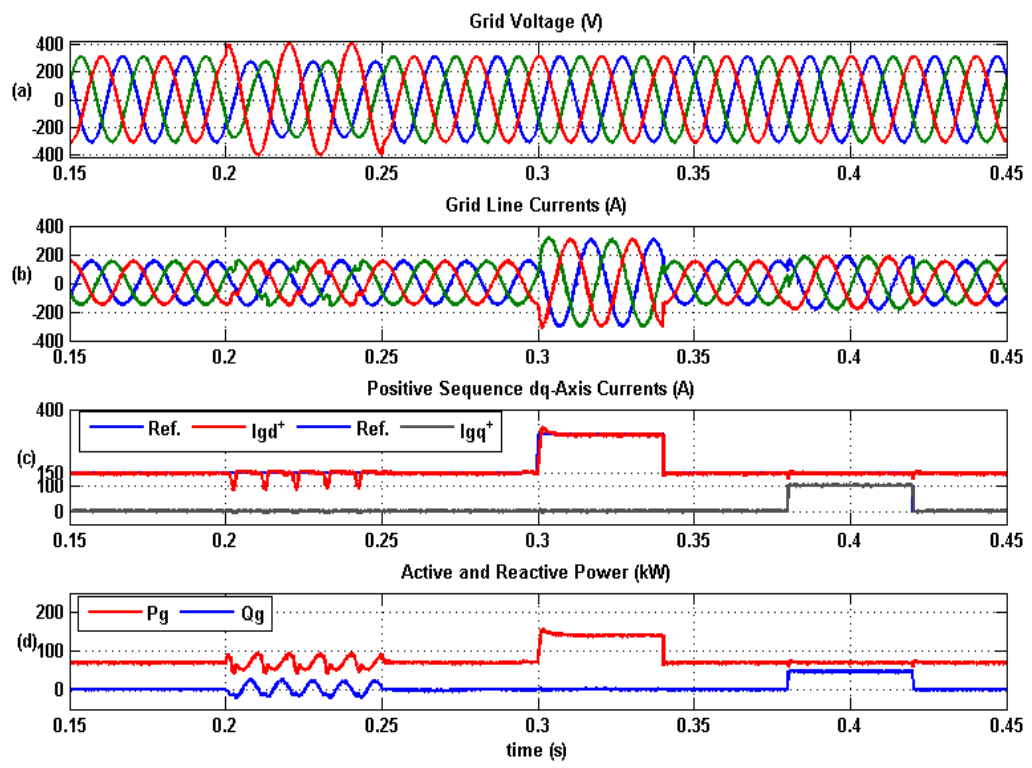

Figure 6. Simulation Results without dual positive and negative sequence controllers (a)Grid Voltage (V) (b) Grid Currents (A) (c)Positive Sequence dq-Axis Currents (A) (d)Pg (kW) and Qg(kVAr) (Simulation A)
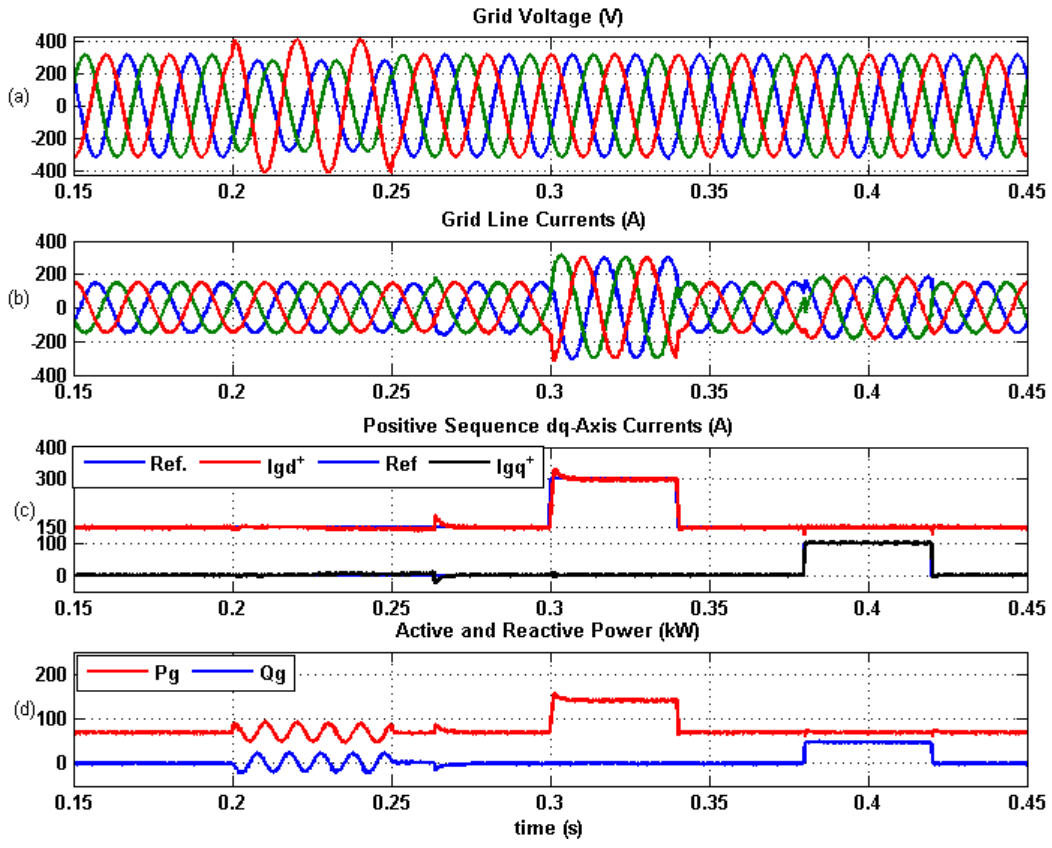

Figure 7. Simulation Results with dual positive and and negative sequence controllers (a)Grid Voltage (V) (b) Grid Currents (A) (c)Positive Sequence dq-Axis Currents (A) (d)Pg (kW) and Qg(kVAr)(Simulation B)

Fig. 8 and Fig. 9 shows the estimated disturbances and negative sequence current components with (Simulation B) and without (Simulation A) negative sequence current controller. Fig.8a and 8b shows the fed forwarded $\hat{\mathrm{f}}_{\mathrm{gd}}^{+}-\hat{\mathrm{f}}_{\mathrm{gq}}^{+}$and $\hat{\mathrm{f}}_{\mathrm{gd}}^{-}-\hat{\mathrm{f}}_{\mathrm{gq}}^{-}$terms. The term $\hat{\mathrm{f}}_{\mathrm{gd}}^{+}$saturates to maximum level at the instant of unbalanced voltage condition to remove steady state current errors. Fig. 8c shows that negative sequence current components are removed at the instant of unbalance voltage generation 
in the grid (Simulation B). Fig. 9a shows the $\hat{\mathrm{f}}_{\mathrm{gd}}^{+}-\hat{\mathrm{f}}_{\mathrm{gq}}^{+}$terms when the negative sequence controller is not enabled at the instant of unbalanced voltage generation (Simulation A). Fig. 9b shows the uncompensated negative sequence current components exists and deteriorates the current waveform as shown in Fig. 6 b (Simulation A).
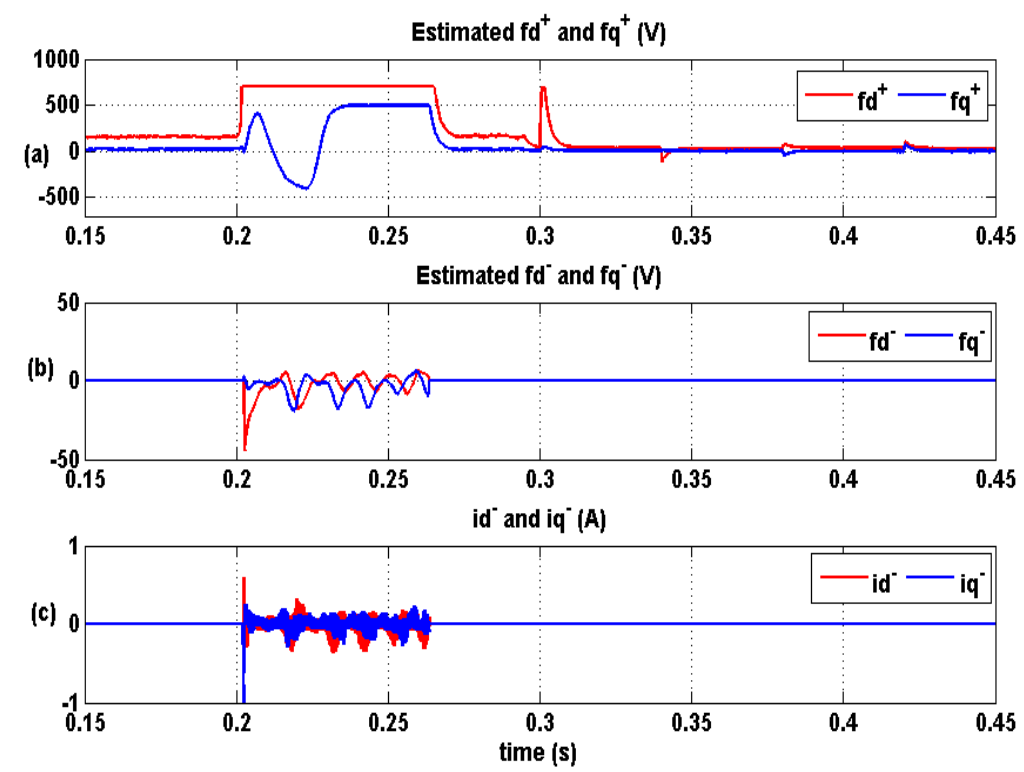

Figure 8. (a) $\hat{\mathrm{f}}_{\mathrm{gd}}^{+}$and $\hat{\mathrm{f}}_{\mathrm{gq}}^{+}(\mathrm{V})(\mathrm{b}) \hat{\mathrm{f}}_{\mathrm{gd}}^{-}$and $\hat{\mathrm{f}}_{\mathrm{gq}}^{-}$(c) $\mathrm{i}_{\mathrm{gd}}^{-}$and $\mathrm{i}_{\mathrm{gq}}^{-}(\mathrm{A})($ Simulation $\mathrm{B})$
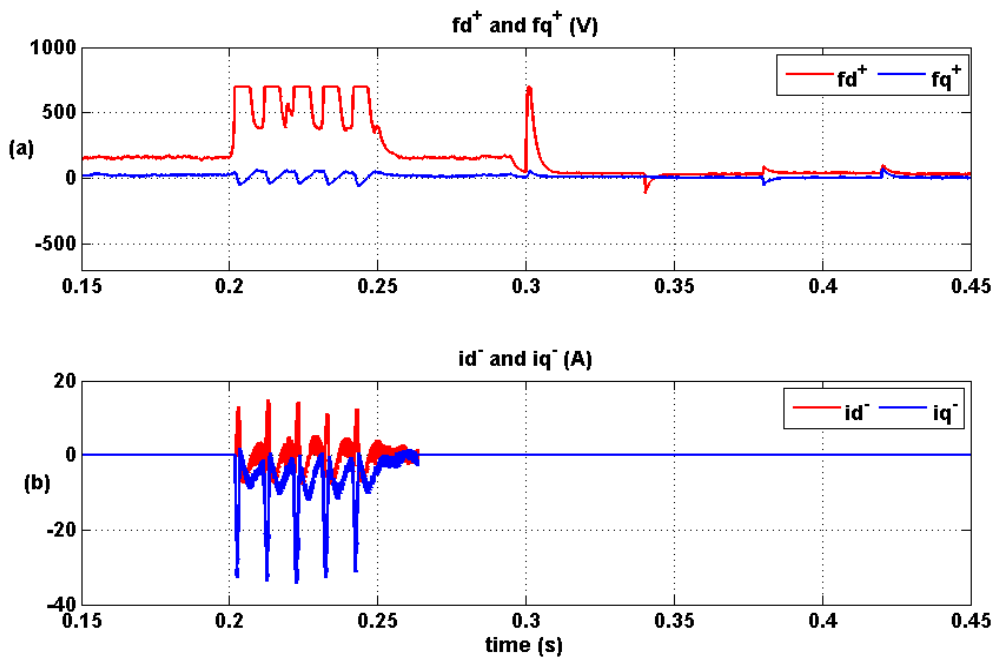

Figure 9. $\hat{\mathrm{f}}_{\mathrm{gd}}^{+}$and $\hat{\mathrm{f}}_{\mathrm{gq}}^{+}(\mathrm{V}),(\mathrm{b}) \mathrm{i}_{\mathrm{gd}}^{-}$and $\mathrm{i}_{\mathrm{gq}}^{-}(\mathrm{A})$ (Simulation $\left.\mathrm{A}\right)$

Fig. 10 and Fig. 11 show the third simulation results to dissipate $\mathrm{P}_{\mathrm{sc} 2}-\mathrm{P}_{\mathrm{ss} 2}$ power oscillations (Simulation C). External PI controllers with reference of $\mathrm{P}_{\mathrm{sc} 2}-\mathrm{P}_{\mathrm{ss} 2}=0$ is enabled as shown in Fig.4. 30\% unbalanced voltage is generated between 0.2-0.0.27s (Fig. 10a). Similar to simulation B negative sequence controller is enabled at predefined unbalanced voltage level. Reference of $i_{\text {gd }}^{+}$is kept at 150A and $\mathrm{i}_{\text {gq }}^{+}$is kept at zero. Fig. 10c shows that $\mathrm{i}_{\text {gd }}^{+}$and $\mathrm{i}_{\text {gq }}^{+}$follows the respective trajectory. 

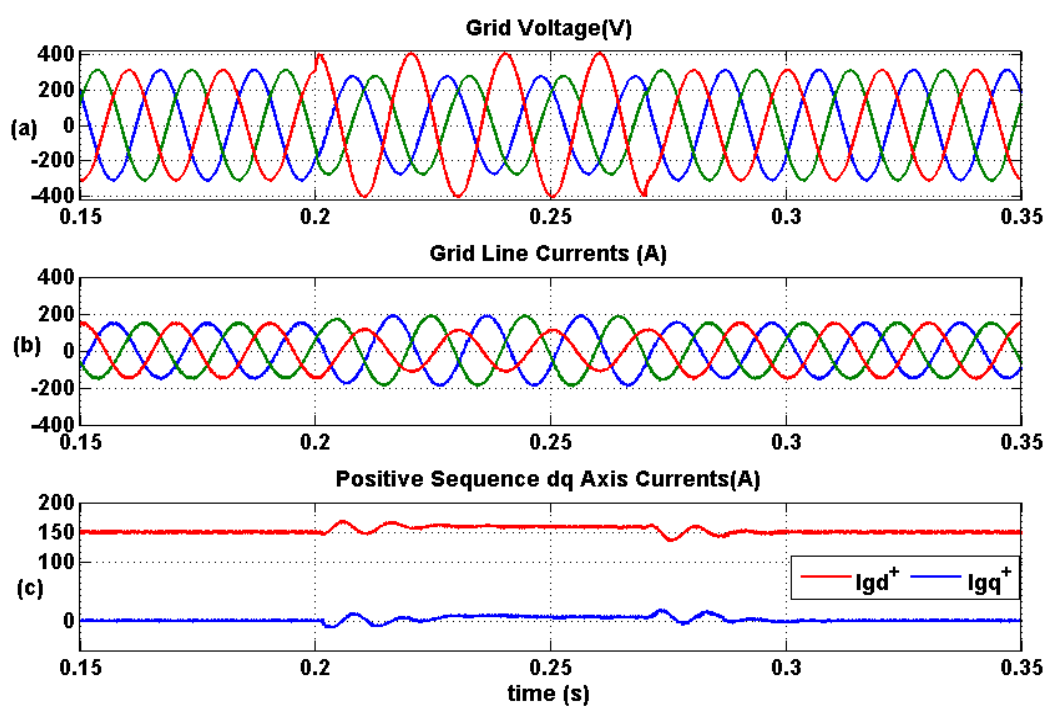

Figure 10. Simulation Results with external Pss2-Psc2 controllers (Simulation C) (a)Grid Voltage (V)

(b) Grid Currents (A) (c)Positive Sequence dq-Axis Currents (A)

Oscillating components $\mathrm{P}_{\mathrm{sc} 2}-\mathrm{P}_{\mathrm{ss} 2}$ are enforced to zero with external PI controllers. PI controller gains could easily be determined with trial and error methods ( $\mathrm{Kp}=1.1 \mathrm{KI}=5.2)$. It can be noted from Eq. 17 that oscillating $\mathrm{P}_{\mathrm{sc} 2}$ and $\mathrm{P}_{\mathrm{ss} 2}$ components can be compensated by internal $\mathrm{i}_{\mathrm{gd}}^{-}$and $\mathrm{i}_{\mathrm{gq}}^{-}$ controllers, respectively. Fig.10a shows the P/Q components. Double frequency oscillations are removed on $\mathrm{P}_{\mathrm{g}}$ by enforcing $\mathrm{P}_{\mathrm{sc} 2}-\mathrm{P}_{\mathrm{ss} 2}$ components to zero that is shown in Fig. 10b. Fig. 10c shows the resultant injected $\mathrm{i}_{\mathrm{gd}}^{-}$and $\mathrm{i}_{\mathrm{gq}}^{-}$components.
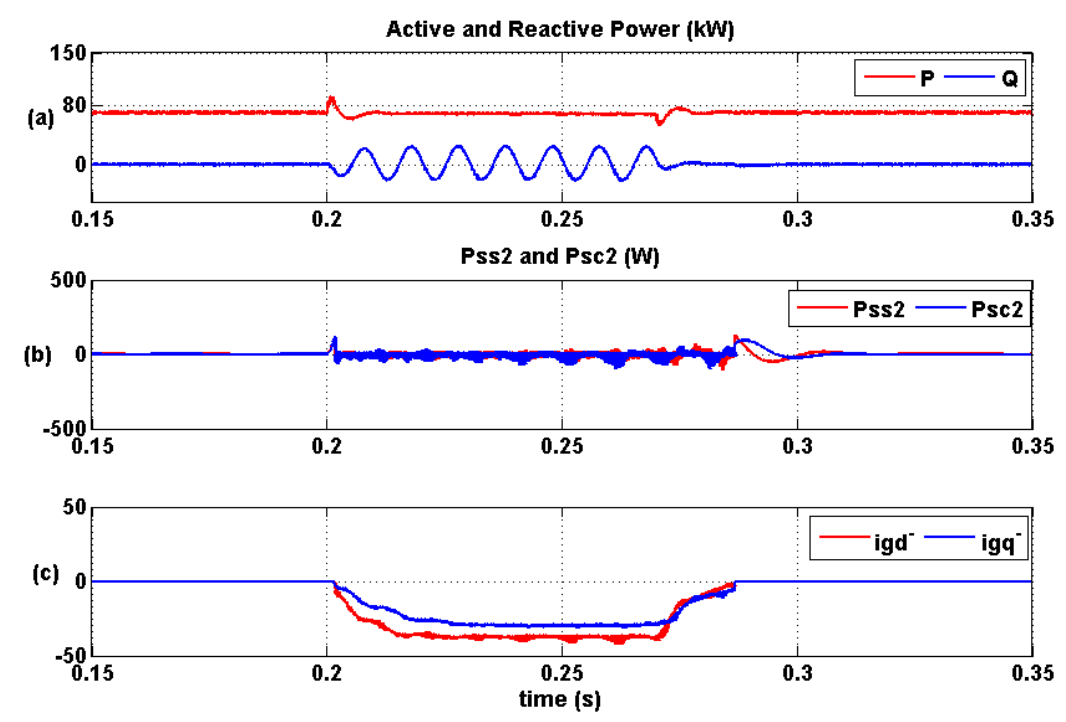

Figure 11. Simulation Results with external Pss2-Psc2 controllers (Simulation C) (a)Pg and Qg) (b) Grid Currents (A) (c)Positive Sequence dq-Axis Currents (A) 


\section{Conclusions}

This study presents a novel grid current controller which utilizes a low pass filter DOb to provide precise control of grid currents under unbalanced grid voltage conditions. The GCI has been modeled in the symmetrical component frames, and estimated disturbance terms are fed forward to current controllers. Hence, the controller structure is parameter independent. P and Q are defined by using the instantaneous power theory and double frequency Pss2 and Psc2 pulsations have been removed. Simulation results show that the method can be applied to real systems to compensate double frequency power oscillations under unbalanced voltage conditions.

Author Contributions: E.Ozsoy, P.Sanjeevikumar has developed the proposed control strategy for grid connected system under distorted conditions. E.Ozsoy, P.Sanjeevikumar, L.Mihet-Popa, F.Ahmad, R.Akhtar, A.Sabanovic involved in further development of the study and implementation strategy. P.Sanjeevikumar, L.Mihet-Popa, A.Sabanovic contributed the expertise in the Grid Connected System for verification of theoretical concepts and validation with obtained results. All authors contributed and involved in framing the final version of the full research article in its current form".

\section{References}

1. IEEE 1547 IEEE Standard for Interconnecting Distributed Resources with Electric Power Systems, IEEE Standard 1547, 2008.

2. EN50160 Voltage Characteristics in Public Distribution Systems, European Union Standard, 2004.

3. Pena, R; Clare, J.C; Asher, G.M. A doubly-fed induction generator using two back-to-back PWM converters and its application to variable speed wind energy system, Proc. Inst. Elect. Eng. B, , 1996, vol. 143, no. 3, pp. 231-241.

4. Rioual, P; Pouliquen, H; Louis H.P. "Control of a PWM rectifier in the unbalanced state by robust voltage regulation," in Proc. 5th Eur. Conf. Power Electron. Appl., Sep. 13-16, 1993, vol. 4, pp. 8-14.

5. Song, H.S; Nam, K. Dual current control scheme for PWM converter under unbalanced input voltage conditions, IEEE Trans. Ind. Electron., Oct. 1999, vol. 46, no. 5, pp. 953-959.

6. Suh, Y; Tijeras, V.; Lipo, T.A. Control scheme in hybrid synchronous stationary frame for PWMAC/DC converter under generalized unbalanced operating conditions, IEEE Trans. Ind. Appl., , Jun. 2006, vol. 42, no. 3, pp. 825-835.

7. Suh, Y; Tijeras, V.; Lipo, T.A. A control method in dq synchronous frame for PWM boost rectifier under generalized unbalanced operating conditions, in Proc. IEEE 33rd Annu. Power Electron. Spec. Conf., 2002, vol. 3, pp. 1425-1430.

8. Teodorescu, R; Blaabjerg, F; M. Liserre, M; Loh, P. C. Proportional Resonant controllers and filters for grid-connected voltage-source converters, IEE Proc. Electric Power Appl., vol. 153, no. 5, pp. 750-762, Sep. 2006.

9. Lascu, C; Asiminoaei, L; Boldea, I; Blaabjerg, F. “High performance current controller for selective harmonic compensation in active power filters," IEEE Trans. Power Electron., Sep. 2007, vol. 22, no. 5, pp. $1826-1835$.

10. Serpa, L.A; Ponnaluri, S; Barbosa, P.M; Kolar, J.W. A modified direct power control strategy allowing the connection of three-phase inverters to the grid through LCL filters, IEEE Trans. Ind. Appl., vol. 43, no. 5, p. 1388-1400, Sep./Oct. 2007.

11. Vazquez, S; Sanchez, J.A; Carrasco, J.M; Leon, J.I; Galvan, E. A model-based direct power control for three-phase power converters, IEEE Trans. Ind. Electron., vol. 55, no. 4, pp. 1647-1657, Apr. 2008.

12. Reyes, M; Rodriguez, P; Vazquez, S; Luna, A; Teodorescu, R; Carrasco, J.M., Enhanced decoupled double synchronous reference frame current controller for unbalanced grid-voltage conditions. IEEE Transactions on power electronics, 2012, 27(9), pp.3934-3943.

13. Dawei,Z; Lie, X; Williams, B.W. Model-based predictive direct power control of doubly fed induction generators, IEEE Trans. Power Electron., Feb. 2010, vol. 25, no. 2, pp. 341-351.

14. Cort'es, P; Rodriguez, J; Antoniewicz, P; Kazmierkowski, M. Direct power control of an AFE using predictive control, IEEE Trans. Power Electron., , Sep. 2008, vol. 23, no. 5, pp. 2516-2553. 
15. Rodriguez, C.P; Timbus, A.V; Teodorescu, R; Liserre, M; Blaabjerg, F. Independent PQ control for distributed power generation systems under grid faults. In IEEE Industrial Electronics 32nd Annual Conference on IECON, 2006, pp. 5185-5190.

16. Wang, Y; Beibei, R; Qing-Chang, Z. Robust Power Flow Control of Grid-connected Inverters, IEEE Transactions on Industrial Electronics, vol. 63, no. 11, pp. 6687-6897, 2016.

17. Ortjohann,E; Arturo,A; Morton, D; Mohd, A; Hamsic, N; Omari,O. Grid-forming three-phase inverters for unbalanced loads in hybrid power systems, In 2006 IEEE 4th World Conference on Photovoltaic Energy Conference, vol. 2, IEEE, 2006, pp. 2396-2399.

18. Vechium, I; Camblong, H; Tapia, G; Curea, O; Dakyo, B. Modelling and control of four-wire voltage source inverter under unbalanced voltage condition for hybrid power system applications. In Power Electronics and Applications, 2005 European Conference on, pp. 10-pp. IEEE, 2005.

19. Chung, S.K. A phase tracking system for three phase utility interface inverters, IEEE Transactions on Power Electronics, 2000, Vol.15, No.3, pp. 431-438,

20. Rodriguez, P; Pou, J; J. Bergas; Candela, J; Burgos, R.P; D.Boroyevich, Decoupled double synchronous reference frame PLL for power converters control, IEEE Transactions on Power Electronics, Vol. 22, No.2, pp.584-592, 2007.

21. Rodriguez, P; Luna,A; Teodorescu, R; Iov, F; Blaabjerg, F. Fault ride-through capability implementation in wind turbine converters using a decoupled double synchronous reference frame PLL, Power Electronics and Applications European Conference, pp. 1-10, IEEE, 2007.

22. Ciobotaru, M; Teodorescu, R; Blaabjerg, F. A new single-phase PLL structure based on second order generalized integrator, June 2006, Power Electronics Specialists Conference, pp. 1-6.

23. Iravani, M.R; Karimi-Ghartemani, M. Online estimation of steady state and instantaneous symmetrical components, IEE Proceedings-Generation, Transmission and Distribution, Vol. 150. No.5, pp.616-622, 2003.

24. Ohnishi, K.; M. Shibata, M; Murakami, T. Motion control for advanced mechatronics, March 1996, IEEE/ASME Transactions on Mechatronics, 1(1), 56-67.

25. Ozsoy, E.E; Golubovic, E; Sabanovic, A; Gokasan, M; Bogosyan, S. A novel current controller scheme for doubly fed induction generators, Automatika, Journal for Control, Measurement, Electronics, Computing and Communications, , 2015, Vol.56 No.2, pp.186-195.

26. Ozsoy, E.E; Golubovic, E; Sabanovic, A; Gokasan, M; Bogosyan, S. Modeling and control of a doubly fed induction generator with a disturbance observer: a stator voltage oriented approach, Turkish Journal of Electrical Engineering \& Computer Sciences, Vol.24, No.3, pp.961-972, 2016.

27. Sabanovic, A; Ohnishi, K. Motion Control Systems , 2011, John Wiley \& Sons.

28. Teodorescu, R; Liserre, M; Rodriguez, P. Grid converters for photovoltaic and wind power systems. Vol. 29.,2011, John Wiley \& Sons.

29. Taravat,S. Modeling and Observer Design of a Nonlinear LCL Filter for Three-Phase Grid-Connected Voltage Source Converter, 2014, LUP Student Papers.

30. Utkin, V; Sabanovic, A; Sliding modes applications in power electronics and motion control systems, Industrial Electronics, 1999. ISIE'99. Proceedings of the IEEE International Symposium on. Vol. 1. IEEE, 1999.

31. H. Akagi, E.H. Watanabe, and M. Aredes. Instantaneous power theory and applications to power conditioning". Vol. 31. John Wiley \& Sons, 2007.

32. Krause, P.C; Wasynczuk, O; Sudhoff, S.D. Analysis of Electrical Machinery and Drive Systems, Second Edition, John WileyESons, IEEE Power Engineering Society, 2002.

33. $\mathrm{Xu}, \mathrm{L}$. Coordinated control of DFIG's rotor and grid side converters during network unbalance, IEEE Transactions on Power Electronics, 2008, vol:23. No.3, pp.1041-1049. 